\title{
JNVEST]GHACJÓN
}

\section{Analysis of chicken fat as adulterant in butter using fourier transform infrared spectroscopy and chemometrics}

\author{
By A. F. Nurrulhidayah ${ }^{\mathrm{a}}$, A. Rohman ${ }^{\mathrm{b}}$, I. Amin ${ }^{\mathrm{a}, \mathrm{c}} \mathbb{}$, M. Shuhaimi ${ }^{\mathrm{a}}$, and A. Khatib ${ }^{\mathrm{d}, \mathrm{e}}$ \\ ${ }^{a}$ Laboratory of Halal Science Research, Halal Products Research Institute, \\ Universiti Putra Malaysia, 43400 Serdang, Selangor, Malaysia \\ ${ }^{\mathrm{b}}$ Research Center of Halal Products and Faculty of Pharmacy, Gadjah Mada University, \\ 55281 Yogyakarta, Indonesia \\ ${ }^{c}$ Department of Nutrition and Dietetics, Faculty of Medicine and Health Sciences, \\ Universiti Putra Malaysia, 43400 Serdang, Selangor, Malaysia \\ ' Laboratory of Natural Product, Institute of Bioscience, Universiti Putra Malaysia, \\ 43400 UPM, Serdang, Selangor, Malaysia \\ ${ }^{\text {e }}$ Faculty of Food Science and Technology, Universiti Putra Malaysia, 43400 Serdang, Selangor, Malaysia. \\ Corresponding author: amin@medic.upm.edu.my
}

\section{RESUMEN}

Análisis de la grasa de pollo como adulterante de la mantequilla usando espectroscopia infrarroja con transformada de Fourier y quimiometría

La mantequilla puede ser adulterada con grasas animales más baratas, como la grasa de pollo (GP). Así, la detección y cuantificación de la adulteración de mantequilla con GP se controló usando transformada de Fourier infrarroja (FTIR), combinada con técnicas quimiométricas de mínimos cuadrados parciales (PLS) en las regiones de frecuencia de $1200-1000 \mathrm{~cm}^{-1}$. Las medidas FTIR se realizaron sobre la mantequilla pura y adulterada con diferentes concentraciones de GP (0-100\% w/w en la mantequilla). La calibración de PLS presenta una buena relación entre los valores reales y los valores pronosticados de FTIR de la GP con un coeficiente de determinación $\left(R^{2}\right)$ de 0.981 . La raíz del error estándar de calibración (RMSEC) durante la validación cruzada (RMSECV) obtenido utilizando seis componentes principales (PC) fueron 2,08 y $4,33 \% \mathrm{v} / \mathrm{v}$, respectivamente.

PALABRAS CLAVE: Calibración multivariante - Espectroscopia FTIR - Grasa animal - Mantequilla - Quimiometría.

\section{SUMMARY}

Analysis of chicken fat as adulterant in butter using fourier transform infrared spectroscopy and chemometrics

Butter may be adulterated with cheaper animal fats, such as chicken fat (CF). Thus, the detection and quantification of butter adulteration with CF was monitored using Fourier transform infrared (FTIR) spectroscopy, combined with chemometric of partial least square (PLS) at the frequency regions of $1200-1000 \mathrm{~cm}^{-1}$. FTIR measurements were made on pure butter and that adulterated with varying concentrations of CF $(0-100 \% \mathrm{w} / \mathrm{w}$ in butter). PLS calibration exhibits a good relationship between actual and FTIR predicted values of CF with a coefficient of determination $\left(R^{2}\right)$ of 0.981 . The root means standard error of calibration (RMSEC) and during cross validation (RMSECV) obtained using six principal components (PCs) are 2.08 and $4.33 \% \mathrm{v} / \mathrm{v}$, respectively.

KEY-WORDS: Animal fat - Butter - Chemometrics FTIR spectroscopy - Multivariate calibration.

\section{INTRODUCTION}

Food adulteration is an addition process of substances which are injurious to health, or by the removal of substances which are nutritious. The driving force behind this process is profit maximization which can be achieved using lowcost substances to partially or wholly substitute with the more expensive ones (Arvaniyoyannis and Tzourous, 2005). The mixing of animal fats with food products is a major concern to certain groups of consumers due to religious obligations and health complications. From religious perspectives, the source of fat that acts as adulterant is a serious issue of concern. In Islamic and Kosher dietary laws, foods containing porcine based substances are strictly forbidden, while in Hinduism, the consumption of beef fats in food is prohibited (Eliasi and Dweyer, 2002, Marikkrar et al., 2005).

Butter is undoubtedly one of the most complex of all edible fats with more than 500 different fatty acids. It is mainly comprised of saturated fatty acids (SFA), followed by monounsaturated fatty acids (MUFA), and small amounts of polyunsaturated fatty acids (PUFA). It has more than 1300 individual triacylglycerols (TAG) (Barron et al., 1990). Commercial butter must have at least $80-82 \%$ pure milk fat, water, and sometimes salt. Milk or cream should be the primary product. Butter is the foremost lipid product of animal 
agriculture in terms of organoleptic qualities, market price, and wide spread use in edible applications. In the U.S., the annual production of butter is slightly above 1 billion pounds (454 million kilograms, 498 million liters) (US Department of Agriculture, 2005). Due to the price difference and the similar properties, the adulteration of butter with animal fat continues to be a risk for consumers in developing countries.

Several methods have been developed for the detection and quantification of adulterants in butter. Numerous authors (De peters 1993, Carisano and Riva 1976, Coleman 1961; Mattson and Luton 1958; Mattson 1963; Jensen et al., 1964) have reported small amounts of beef tallow incorporated into butter by evaluating the fatty acid composition of the monoglycerides acquired by enzymatic hydrolysis. The addition of beef tallow in butter has been reported by Solimen and Yoones (1986) by determining the cholesterol esters and diglycerides. Currently, Precht (1991) and Mariani et al., (1990) have reported the triglyceride composition of various butter samples. The detection of $1-3 \%$ vegetable and $3-5 \%$ animal fats can be made using statistical parameters. All these methods are only applied to the natural components of fats. However, butter can also contain substances deriving from the refining processes (Lanzón et al., 1989). Therefore, the development of a rapid, accurate, inexpensive analytical technique which is capable of detecting such adulteration in butter is pertinent and highly demanded.

Nowadays, the application of Fourier transformed infrared (FTIR) spectroscopy has emerged, mainly in food studies and has predominantly become a useful analytical tool in the study of edible fats and oils (Guillén and Cabo, 2000). FTIR spectroscopy has received great attention in the quantitative analysis of fats and oils over the years, due to the main advantage of easy sample preparation with reduced or no-sample pre-treatment steps (Sherazi et al., 2007, Baeten and Dardenne, 2002). It is used for the high-throughput analysis of milk-based food components that rapidly allows real-time measurements at all stages of production without requiring special skills from users. This technique can be easily applied in fundamental research, control laboratories and industrial settings (Karoui and De Baerdemaeker, 2007, Subramaniam and RodriguezSaona, 2010). There have been several studies concerning the classification, characterization, and authentication studies of edible fats and oils using IR spectroscopy (Dobson, 2001).

In combination with prevalent chemometric techniques, FTIR spectroscopy methods have been emphasized for the quantitative analysis of various food products such as lard in cake formulation (Syahariza et al., 2005), biscuits (Che Man et al., 2011), cocoa butter (Che Man et al., 2011) and mixtures of lards with other animal fats (Che Man and Mirghani, 2001). These techniques are also proven to assess the overall levels of butterfat and butyric acids as an indirect indicator of adulteration (Heussen et al., 2007). The adulteration of butter fat with foreign fat could be detected by observing the FTIR spectra at the specific wavelength due to the ratios of cis-unsaturations of fatty acid moieties as reported by Sato et al., (1990). However, there is no information available related to the use of FTIR spectroscopy coupled with chemometrics for the analysis of butter adulterated with chicken fat. Therefore, in this study, we proposed FTIR spectroscopy combined with multivariate analysis for the detection and quantification of chicken fat using partial least square (PLS).

\section{MATERIALS AND METHODS}

\subsection{Sample preparation}

Lard, beef, mutton and chicken were obtained through the rendering process of the adipose tissues of the corresponding animals. The rendering processed was carried out according to Rohman and Che Man (2009a). Butter samples were extracted according to the AOAC official method 920.118 (2000). The extracted samples were kept in glass vials under refrigerated conditions $\left(-20^{\circ} \mathrm{C}\right)$ until used for analysis. Infrared spectra were collected for each sample to develop a classification model.

\subsection{Calibration and Validation}

The calibration samples, composing of a number of standard or training sets consisting of chicken fat (CF) in butter at concentration ranges of $0-100 \% \mathrm{v} / \mathrm{v}$, were prepared. For validation, a series of independent samples was built to evaluate the predictive ability of the developed calibration model. The spectra of pure butter and CF as well as their mixtures were analyzed using FTIR spectroscopy. The wavelength regions where the variations were observed were chosen for developing the PLS model in order to quantify $\mathrm{CF}$ in butter.

\subsection{FTIR instrumental analysis}

The FTIR spectra of samples (either pure or admixtures) were measured using $A B B$ 3000 FTIR spectrometer (Canada) equipped with a deuterated triglycine sulphate (DTGS) detector and $\mathrm{KBr} / \mathrm{Germanium}$ as beam splitter. The instrument was connected to the Horizon MB software. The sampling compartment was attenuated total reflectance, producing 12 internal reflections with a penetration depth (infrared beam) of $2.0 \mu \mathrm{m}$, composed of zinc selenide ( $\mathrm{ZnSe}$ ) crystals with a refractive index of 2.4 at $1000 \mathrm{~cm}^{-1}$. FTIR spectra were collected at the mid-infrared region $\left(4000-650 \mathrm{~cm}^{-1}\right)$, using 32 scans at a resolution of $8 \mathrm{~cm}^{-1}$. These spectra were subtracted against the background of air spectrum. After every scan, a background of new reference air spectrum was taken. These spectra were recorded as absorbance values at each data point in triplicate. 


\subsection{Statistical and chemometrics analysis}

The Chemometric analysis of PLS was done using the software Horizon MB (Canada). The leave one out cross validation procedure was used to verify the calibration model. The calibration of performance of PLS was assessed using the values of root mean standard error of calibration (RMSEC) and coefficient of determination $\left(R^{2}\right)$. In addition, $R^{2}$ and root mean standard error of prediction (RMSECV) were used for the evaluation of the validation capacity of PLS.

\subsection{Fatty acid analysis}

The fatty acid (FA) compositions of butter and other animal fats were determined using a gas chromatograph (Shimadzu GC-2010, Shimadzu Corp., Tokyo, Japan), equipped with flame ionization detector. The oven temperature was programmed as follows: the initial temperature was $100^{\circ} \mathrm{C}$ (held for $1 \mathrm{~min}$ ), then ramped up to $180^{\circ} \mathrm{C}\left(8^{\circ} \mathrm{C} \mathrm{min}^{-1}\right)$, increased from 180 to $240^{\circ} \mathrm{C}$ $\left(10^{\circ} \mathrm{C} \mathrm{min}^{-1}\right)$, and finally held at $240^{\circ} \mathrm{C}$ for $5 \mathrm{~min}$. The temperatures of detector and injector were maintained at $240^{\circ} \mathrm{C}$ during the analysis. The flow rate of carrier gas (helium) was $6.8 \mathrm{~mL} \mathrm{~min}^{-1}$. Before analysis, the samples were treated with sodium methoxyde to form FAMEs according to the method described by Chin et al., (2009). The column, oven and other conditions used during FA analysis are similar to those reported by Rohman and Che Man (2009b). The qualitative analysis of FAMEs in samples was carried out by comparing retention times of the peaks with those of FAMEs standards. The quantification of FAs was performed using the technique of internal normalization and expressed as percentages based on peak areas.

\section{RESULTS AND DISCUSSION}

The analyses focused on the measurement of the FTIR spectra of butter and chicken fat in the $4000-650 \mathrm{~cm}^{-1}$ spectral region. The characteristic infrared spectra of butter and CF are shown in Figure 1. The absorption bands of water, corresponding to the $\mathrm{O}-\mathrm{H}$ groups, were observed in the region of $1600-1500 \mathrm{~cm}^{-1}$, which can affect the amide I signal at about $1650 \mathrm{~cm}^{-1}$ (Karoui and De Baerdemaker, 2007; Rodriguez et al., 2006). In agreement with Koca et al., (2010), strong absorptions were observed at 2900 and $2800 \mathrm{~cm}^{-1}$, respectively, corresponding to $\mathrm{C}-\mathrm{H}$ $\left(\mathrm{CH}_{2}\right.$ and $\left.\mathrm{CH}_{3}\right)$ stretching vibrations. Moreover, a weak signal at $3000 \mathrm{~cm}^{-1}$ associated with $\mathrm{C}=\mathrm{C}-\mathrm{H}$ stretching groups of cis-unsaturation was observed. At $1745 \mathrm{~cm}^{-1}$, another strong band was present, which is reported to be associated with $-\mathrm{C}=\mathrm{O}$ stretching vibrations of acids and esters (Lema Garcia et al., 2010). This band and the next at $1460 \mathrm{~cm}^{-1}$ arising from $\mathrm{N}-\mathrm{H}$ bending vibration are most likely associated with the amide I and amide II of proteins (Karoui and De Baerdemaker, 2007; Rodríguez et al., 2006). In the last part of the spectra $\left(1300-1000 \mathrm{~cm}^{-1}\right)$, stretching vibrations of the $\mathrm{C}-\mathrm{O}$ bond of esters and bending vibrations of a methylene group were present (Lema García et al., 2010).The band at $966 \mathrm{~cm}^{-1}$, associated with $-\mathrm{HC}=\mathrm{CH}$ out-of-plane deformation vibrations, has been previously reported as a marker band for the determination of trans-fats.

Butter contains more saturated fatty acids than those in CF (Table 1), especially myristic acid (C14:0), as determined using gas chromatography. Meanwhile, CF has more unsaturated fatty acids, especially linoleic acid (C18:2), compared with butter. The presence of unsaturated fatty acids in CF can also be observed in its FTIR spectrum at

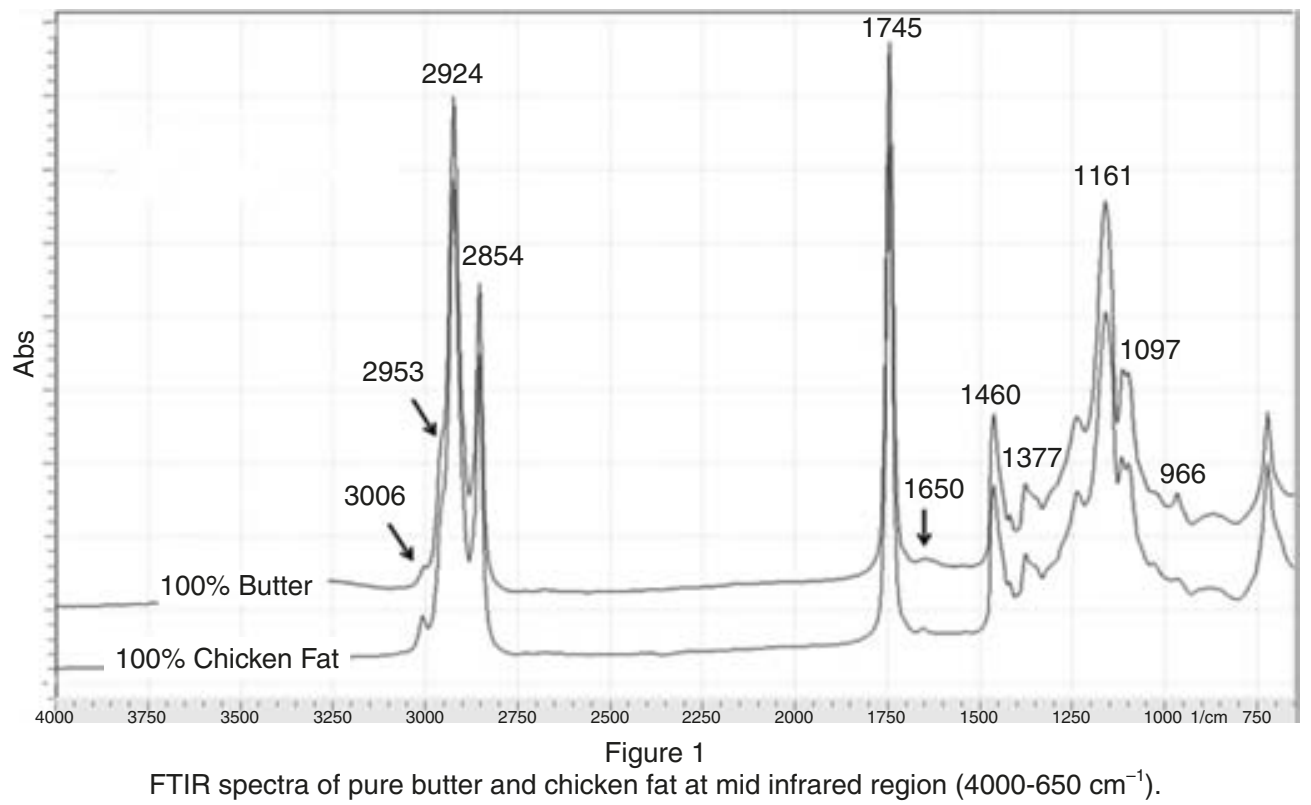


Table 1

Fatty acid compositions of butter and three animal fats (BF, CF, and MF) determined using $\mathrm{GC}$ with flame ionization detector

\begin{tabular}{crcccc}
\hline FA $^{\dagger}$ & \multicolumn{1}{c}{ Butter } & Chicken Fat (CF) & Beef Fat (BF) & Mutton Fat (MF) & Lard (LD) \\
\hline C4:0 & $2.34 \pm 0.03$ & $0.00 \pm 0.00$ & $0.00 \pm 0.00$ & $0.00 \pm 0.00$ & $0.00 \pm 0.00$ \\
C6:0 & $1.63 \pm 0.02$ & $0.00 \pm 0.00$ & $0.00 \pm 0.00$ & $0.00 \pm 0.00$ & $0.00 \pm 0.00$ \\
C8:0 & $1.04 \pm 0.01$ & $0.00 \pm 0.00$ & $0.00 \pm 0.00$ & $0.00 \pm 0.00$ & $0.00 \pm 0.00$ \\
C10:0 & $2.34 \pm 0.01$ & $0.00 \pm 0.00$ & $0.00 \pm 0.00$ & $0.00 \pm 0.00$ & $0.00 \pm 0.00$ \\
C12:0 & $9.79 \pm 0.03$ & $0.83 \pm 0.01$ & $0.00 \pm 0.00$ & $0.00 \pm 0.00$ & $0.05 \pm 0.04$ \\
C14:0 & $14.79 \pm 0.05$ & $1.11 \pm 0.00$ & $2.28 \pm 0.01$ & $3.87 \pm 0.04$ & $1.11 \pm 0.02$ \\
C15:0 & $0.00 \pm 0.00$ & $0.00 \pm 0.00$ & $0.74 \pm 0.00$ & $1.05 \pm 0.01$ & $0.74 \pm 0.00$ \\
C16:0 & $31.29 \pm 0.05$ & $25.74 \pm 0.00$ & $26.91 \pm 0.03$ & $33.77 \pm 0.23$ & $23.37 \pm 0.22$ \\
C16:1 & $0.00 \pm 0.00$ & $5.90 \pm 0.02$ & $1.15 \pm 0.00$ & $1.31 \pm 0.02$ & $1.50 \pm 0.02$ \\
C17:0 & $0.00 \pm 0.00$ & $0.00 \pm 0.00$ & $2.57 \pm 0.01$ & $2.92 \pm 0.03$ & $0.53 \pm 0.00$ \\
C17:1 & $0.00 \pm 0.00$ & $0.00 \pm 0.00$ & $0.45 \pm 0.00$ & $0.75 \pm 0.01$ & $0.36 \pm 0.01$ \\
C18:0 & $11.62 \pm 0.04$ & $5.60 \pm 0.68$ & $34.05 \pm 0.02$ & $47.05 \pm 0.39$ & $13.26 \pm 0.18$ \\
C18:1 & $22.77 \pm 0.13$ & $44.69 \pm 5.43$ & $30.94 \pm 0.04$ & $7.78 \pm 0.02$ & $40.15 \pm 0.31$ \\
C18:2 & $1.64 \pm 0.00$ & $20.16 \pm 0.02$ & $0.38 \pm 0.02$ & $0.92 \pm 0.29$ & $17.29 \pm 0.09$ \\
C18:3 & $0.74 \pm 0.00$ & $1.04 \pm 0.00$ & $0.53 \pm 0.00$ & $0.57 \pm 0.50$ & $0.89 \pm 0.02$ \\
\hline
\end{tabular}

$\mathrm{FA}=$ fatty acid; ${ }^{\dagger}$ Each value in the table represents the means of triplicate analysis.

$3006 \mathrm{~cm}^{-1}$ which indicates the higher amount of unsaturated fatty acids. This method was developed for PLS analysis which relies on the exploitation of these small changes in the regions of interest, namely at frequencies of $1200-1000 \mathrm{~cm}^{-1}$.

Taking into account the difference between the butter and CF spectra, it is obvious that peak intensities at $1200-1000 \mathrm{~cm}^{-1}$ are different. Therefore, these frequencies were selected to be optimized for the analysis of CF in butter, because FTIR spectra variation was observed between CF and butter.

\subsection{Quantification of chicken fat in butter}

Absorbencies of CF with concentrations ranging from $0 \%-100 \%$ in butter were recorded as a calibration model. Partial Least Square (PLS) was used for making a relationship between actual and predicted values of CF $(\% \mathrm{v} / \mathrm{v})$ in butter. Frequencies at selected fingerprint (1200$1000 \mathrm{~cm}^{-1}$ ) were exploited for quantitative analysis. The relationship between actual value (x-axis) and the FTIR predicted value of CF in the PLS calibration model is shown in Figure 2. A good

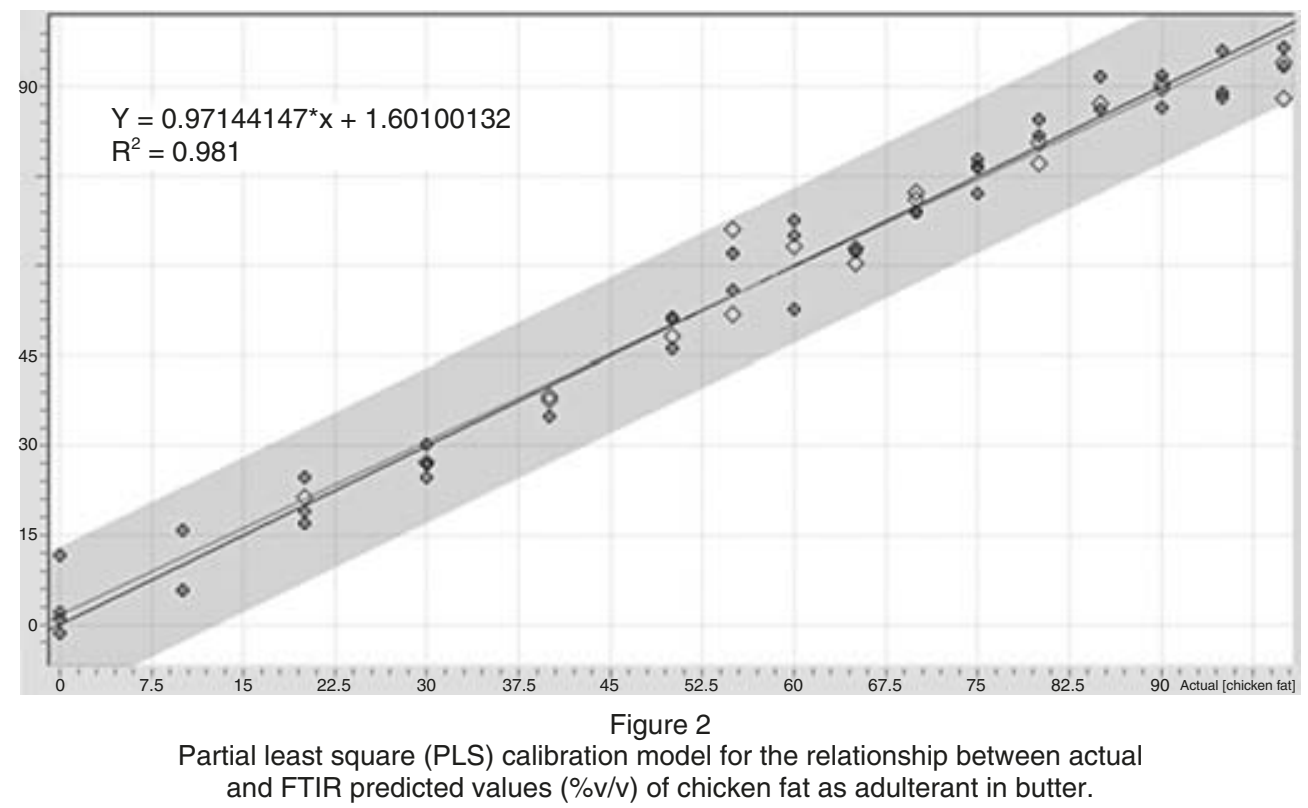


linear regression $y=0.971 x+1.601 ;$ was obtained with $\mathrm{R}^{2}$ and RMSEC values at 0.981 and $2.08 \%$ $\mathrm{v} / \mathrm{v}$, respectively. $\mathrm{R}^{2}$ values defined the relationship between the actual and predicted value of the analyte of interest (CF). This means that the nearer the $R^{2}$ value is to unity, the better the relationship. Meanwhile, RMSEC refers to the root mean error square calibration uncertainty. The smaller the RMSEC value, the better the calibration model.

The goodness of a calibration can be summarized by two values: the percent of variance explained by the model and the Root Mean Square Error in Calibration (RMSEC). The former, being a "normalized" value, gives a first idea about how much of the variance of the data set is "captured" by the model; the latter, being an absolute value to be interpreted the same way as a standard deviation is, giving information about the magnitude of error (Leardi, 2002).

The main problem in PLS algorithm is over fitting, which means that the PLS model produces a good model in the calibration dataset, but the model will not perform well in validation datasets using similar samples. In order to evaluate the over-fitting, a procedure of cross validation using the leave-one-out technique was used (Wang et al., 2006). The PLS calibration model was further subjected to cross validation using the "leave one out" technique. For the validation procedure, other samples prepared in the laboratory were used to minimize the validation error and to provide an estimate of the overall accuracy of validations. The root mean square error of cross validation (RMSECV) obtained was $4.33 \% \mathrm{v} / \mathrm{v}$.

The confirmation and validation of the analysis region used for developing the PLS model were performed by computing the predicted residual error sum of squares (PRESS) values for different factors or principal components (PCs). The PRESS is a value direct measure on how well a calibration can predict the concentration left out during a cross validation (Smith, 2002), PRESS informed that the optimal factor number is 6, as revealed in Figure 3, which illustrates how the RMSEC obtain a stable value, minimally after six factors. This confirms that the spectral region used for developing the PLS model for the quantification of CF exhibits significant correlation with its concentration. From residual analysis as shown in Figure 4, it can be stated that errors occurring during analysis are random.

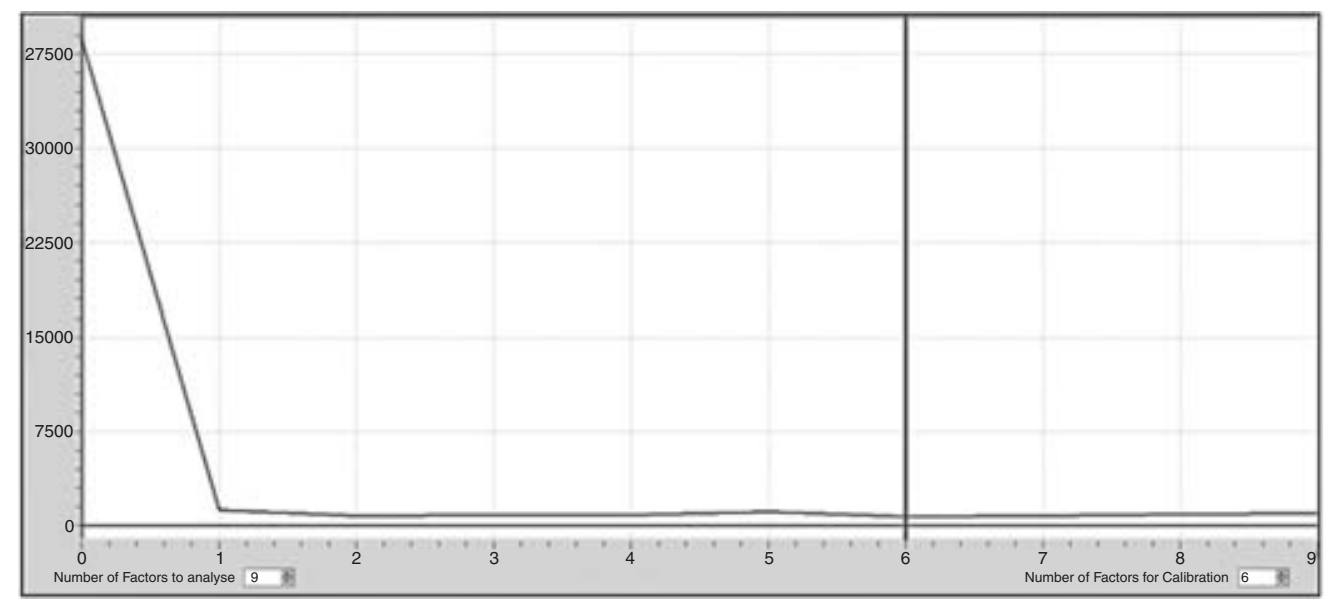

Figure 3

Number of factor for modeling PLS calibration.

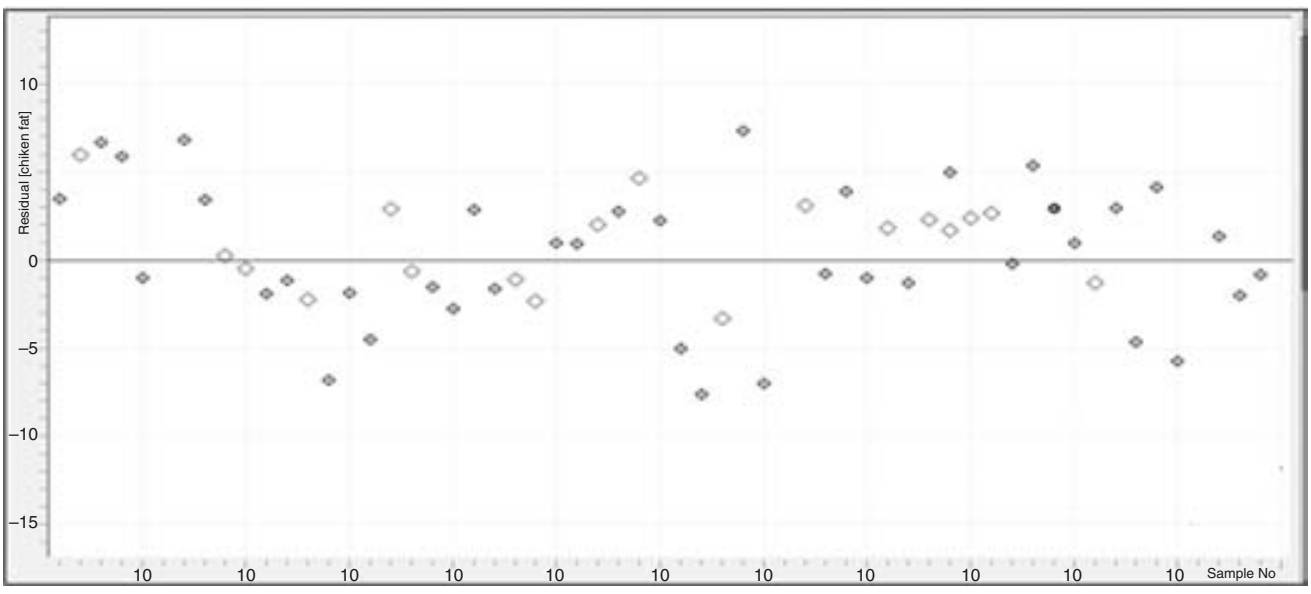

Figure 4

The residual analysis for the relationship between actual and FTIR predicted values of chicken fat as adulterant in butter. 


\section{CONCLUSION}

It can be concluded that FTIR spectroscopy in combination with chemometrics can be used to detect and to quantify the adulteration of butter and CF. The level of adulterants was successfully determined with the aid of a PLS calibration model. PLS can be successfully used to quantify the level of CF adulterant at the selected fingerprint region of $\left(1200-1000 \mathrm{~cm}^{-1}\right)$.

\section{ACKNOWLEDGEMENTS}

The first author acknowledges MyPhD for its scholarship to pursue a PhD program in Halal Products Research Institute, University Putra Malaysia (UPM). Integrated Research and Testing Laboratory, Gadjah Mada University (LPPT-UGM) is also acknowledged for providing the FTIR spectrophotometer to make this study possible.

\section{REFERENCES}

AOAC (Association of Official Analytical Chemists) (2000). Official methods of analysis of AOAC International $\left(17^{\text {th }}\right.$ ed.). Gaithersbug, MD: AOAC International (Official Method 920.118).

Arvaniyoyannis IO, Tzouros NE. 2005. Implementation of quality control methods in conjunction with chemometrics toward authentication of dairy products. Crit. Rev. Food Sci. Nutr. 45, 231-249.

Baeten V and Dardenne P. 2002. Spectroscopy: Developments in instrumentation and analysis. Grasas Aceites 53, 45-63.

Barron LJR, Hierro MTG, Santa-María G. 1990. HPLC and GLC analysis of the triglyceride composition of bovine, ovine and caprine milk fat. J. Dairy Res. 57, 517-526.

Carisano A, Riva M. 1976. Method chromatograficoper reveal sotisticazioni butter. Riv. Ita L Sost. Grasse $\mathbf{5 2}$ 297-300.

Che Man YB, Mirghani MES. 2001. Detection of lard mixed with body fats of chicken, lamb, and cow by Fourier transform infrared spectroscopy. J. Am. Oil Chem. Soc. 78, 753-761.

Che Man YB, Syahariza ZA, Rohman A. 2011. Discrimination analysis of selected edible fats and oils and those in biscuit formulation using FTIR spectroscopy. Food Anal. Method 4, 404-409.

Chin ST, Che Man YB, Tan CP, Hashim DM. 2009. Rapid profiling of animal derived fatty acids using fast GCxGC coupled to time of flight mass spectrometry. J. Am. Oil Chem. Soc. 86, 949-958.

Coleman MH. 1961. Further studies on the pancreatic hydrolysis of some natural fats. J. Am. Oil Chem. Soc. 38, 685-688.

De Peters EJ, Proceedings Cornell Nutrition Conference for Feed Manufacturers, (1993) p. 199.

Dobson G. 2001. Spectroscopy and spectrometry of lipids- Part 1. Eur. J. Lipid Sci. Technol. 103, 815-840.

Dobson G. 2001. Spectroscopy and spectrometry of lipids- Part 2. Eur. J. Lipid Sci. Technol. 104, 36-68.

Eliasi JR and Dwyer JT. 2002. Kosher and Halal: Religious observances affecting dietary intake. J. Am. Dietetic. Assoc. 102, 911-913.
Guillén MD, Cabo. 2000. Some of the most significant changes in the Fourier transform infrared spectra of edible oils under oxidative conditions. J. Sci. Food Agric. 80, 2028-2036.

Heussen PCM, Janssen HG, Samwel IBM, van Duynhoven JPM.2007. The use of multivariate modelling of near infrared spectra to predict the butterfat content of spreads. Anal. Chim. Acta 595, 176-181.

Jensen RG, Sampugna J, Pereira RL, Chandan RC, Shahani KM. 1964. Specificity of milk lipase for a butryl glyceride. J. Dairy Sci. 47, 1012-1013.

Karoui R, De Baerdemaeker J. 2007. A review of the analytical methods coupled with chemometric tools for the determination of the quality and identity of dairy products. Food Chem. 102, 621-640.

Koca N, Kocaoglu-Vurma NA, Harper WJ, RodriguezSaona LE. 2010. Application of temperature controlled attenuated total reflectance mid infrared (ATR-MIR) spectroscopy for rapid estimation of butter adulteration. Food Chem. 121, 778-782.

Lanzón A, Cert A, Albi T. 1989. Detection of refined olive oil in virgin olive oil. Grasas Aceites 40,385-388.

Leardi R. 2002. Chemometrics: From Classical to Genetic Algorithms. Grasas y Aceites. 53, 115-127.

Lerma-García MJ, Gori A, Cerretani L, Simó-Alfonso EF, Caboni MF. 2010. Classification of Pecorino Cheeses produced in Italy according to their ripening time and manufacturing technique using Fourier transform infrared spectroscopy. J. Dairy Sc. 93, 4490-4496.

Mariani C, Contarini G, Zucchetti S, Toppino PM. 1990. Significance of minor components of milk fat. J. High Resol. Chromatogr. 13, 356-360.

Marikkar JMN, Ghazali HM, Che Man YB, Peiris TSG, Lai OM. 2005. Distinguishing lard from other animal fats in admixtures of some vegetable oils using liquid chromatographic data coupled with multivariate data analysis Food Chem. 91, 5-14.

Mattson FH. 1963. The specific distribution of unsaturated fatty acids in the triglycerides of plants. J. Lipid Res. 4, 392-396.

Mattson J, Luton ES. 1958. The specific distribution of fatty acids in the glycerides of animal and vegetable fats. J. Biol. Chem. 233-868.

Precht D. 1991. Detection of adulterated milk fat by fatty acid and triglyceride analysis. Fett Wiss. Technol. 93, 538-544.

Rodríguez-Saona LE, Koca N, Harper WJ, Álvarez VB. 2006. Rapid determination of Swiss cheese composition by fourier transform infrared/attenuated total reflectance spectroscopy. J. Dairy Sci. 89, 1407-1412.

Rohman A, Che Man YB. 2009a. Analysis of cod-liver oil adulteration using Fourier transform infrared (FTIR) spectroscopy. J. Am. Oil Chem. Soc. 86, 1149-1153.

Rohman A, Che Man YB. 2009b. Monitoring of virgin coconut oil (VCO) adulteration with palm oil using Fourier transform infrared (FTIR) spectroscopy, $J$. Food Lipids 16, 618-628.

Sato T, Kawano S, Iwamoto M. 1990. Detection of foreign fat adulteration of milk fat by near infrared spectroscopic method. J. Dairy Sc. 73, 3408-3413.

Sherazi, STH, Mahesar SA, Bhanger MI, van de Voort FR, Sedman J. 2007. Rapid determination of free fatty acids in poultry feed lipid extracts by SB-ATRFTIR spectroscopy. J. Agric. Food Chem. 55, -.

Smith BC. 2002. Quantitative spectroscopy: Theory and practice, Amsterdam: Academic Press.

Solimen MA, Yoones NA. 1986. Adulterated butter fat: fatty acid composition of triglycerides and 2-monoglycerides J. Am. Oil Chem. Soc. 63, 248-250. 
Subramanian A, Rodriguez-Saona L. 2010. Chemical and instrumental approaches to cheese analysis. Adv. Food Nutr. Res. 59, 167-213.

Syahariza ZA, Che Man YB, Selamat J, Bakar J. 2005. Detection of lard adulteration in cake formulation by Fourier transform infrared (FTIR) spectroscopy. Food Chem. 92, 365-371.

U.S. Department of Agriculture, (2005) Agricultural Statistics, Washington, DC, www.usda.gov/nass/pubs/agr05/05_ ch8.PDFm Table 8-33 (retrieved May 26, 2009).
Wang L, Lee FSC, Wang X, He Y. 2006. Feasibility study of quantifying and discriminationg soybean oil adulteration in camellia oils by attenuated total reflectance MIR and fiber optic diffuse reflectance NIR. Food Chem. 95, 529-536.
Recibido: 27/7/12 Aceptado: $18 / 2 / 13$ 